\title{
Risk Factors in Pancreatic Adenocarcinoma: the Interrelation with Familial History and Predictive Role on Survival
}

\author{
Livia Petrusel $^{1,2}$, Maria Bilibou ${ }^{3}$, Vasile Drug ${ }^{3,4}$, Daniel Corneliu Leucuta $^{2,5}$, Radu Seicean ${ }^{2,6}$, Calin Cainap ${ }^{2,7}$, \\ Andrada Seicean ${ }^{1,2}$
}

\author{
1) Department of \\ Gastroenterology, Institute \\ of Gastroenterology and \\ Hepatology, Cluj-Napoca \\ 2) Iuliu Hatieganu University \\ of Medicine and Pharmacy, \\ Cluj-Napoca \\ 3) Department of \\ Gastroenterology, Institute \\ of Gastroenterology and \\ Hepatology, Emergency \\ Hospital Iași \\ 4) Grigore T. Popa University \\ of Medicine and Pharmacy, \\ Iași \\ 5) Medical Informatics and \\ Biostatistics Department, Cluj- \\ Napoca \\ 6) First Surgical Clinic, Cluj- \\ Napoca \\ 7) Ion Chiricuta Oncology \\ Institute Cluj-Napoca, \\ Romania
}

\begin{abstract}
Background \& Aims: Pancreatic cancer is associated with poor survival and quality of life. In Romania the prognostic influence of known risk factors for pancreatic adenocarcinoma, such as age, smoking, chronic pancreatitis, diabetes mellitus, and obesity is little known. Their importance in developing cancer in families with a history of adenocarcinoma is less studied. This study aims to assess the risk factors in pancreatic ductal adenocarcinoma, in familial pancreatic adenocarcinoma, in neuroendocrine tumors and to evaluate their predictive role on survival.

Methods: We performed a prospective bicentric study of patients with pancreatic tumors detected in transabdominal imaging; we assessed the risk factors and their possible association with survival.

Results: 312 pancreatic cancer patients (279 with pancreatic ductal adenocarcinoma and 24 patients with neuroendocrine tumors, and nine patients with other malignant types) and 312 controls were included. The median body mass index was significantly higher in patients with neuroendocrine tumors. Positive family history for pancreatic cancer was found in $4 \%$ of patients with pancreatic cancer. The risk for familial pancreatic carcinoma was associated with the presence of new-onset diabetes (OR: 4.64, $\mathrm{p}=0.018$ ). The multivariate logistic analysis suggested that advanced age (OR: 1.67), smoking (OR: 1.67), low body mass index (OR: 12.07), and diabetes (OR: 3.91) were risk factors for pancreatic cancer. The overall survival analysis after adjustment for age and tumor stage showed only advanced tumoral stage $(\mathrm{HR}=1.6, \mathrm{p}=0.003)$ and metastasis as independent predicting factors $(\mathrm{HR}=1.67, \mathrm{p}<0.001)$.

Conclusion: Our study suggests that diabetes, smoking, underweight, and age over 60 years are risk factors for pancreatic cancer. Patients with a family history of pancreatic cancer, especially those with new-onset diabetes, should be followed carefully and considered for screening. Only an advanced tumor stage was associated with poor overall survival for patients with pancreatic ductal adenocarcinoma.
\end{abstract}

Key words: pancreatic cancer - neuroendocrine tumor - familial pancreatic carcinoma - risk factor - obesity - survival.

Abbreviations: BMI: body mass index; CT: computed tomography; EUS: endoscopic ultrasonography; FNA: fine needle aspiration; HBV: hepatitis B virus; HCV: hepatitis C virus; OS: overall survival; PC: pancreatic cancer; PDAC: pancreatic ductal adenocarcinoma; NET: neuroendocrine tumor; US: ultrasonography.

\section{INTRODUCTION}

Pancreatic cancer (PC) has one of the highest mortality rates among malignancies, with only a $5-7 \%$ survival at five years, despite advances in surgery, chemotherapy, and radiotherapy [1]. Worldwide, the incidence and mortality have been increasing, especially in developed countries [2,3].
Pancreatic cancer is the fourth leading cause of cancer death in the United States [4], and the sixth leading cause of cancer death in Europe [5].

Unfortunately, PC is an aggressive type of cancer, and at the time of diagnosis, $80 \%$ of patients have locally advanced or metastatic PC [6].

As there are no screening tests for early detection of PC, it is important to explore the risk factors, such as genetic factors (taking into consideration that $5-10 \%$ of cases have a familial history of PC [7-10]) and the modifiable risk factors which include smoking, non-hereditary chronic pancreatitis, obesity, long-standing diabetes mellitus [6], alcohol consumption, 
decreased physical activity, increased intake of red or processed meat and inadequate intake of fruits and vegetables, certain abdominal surgeries and some infections $[11,12]$. For example, survival is negatively associated with smoking [13], and the risk rises when it is associated with familial pancreatitis history [14]. New-onset diabetes may be an early marker of pancreatic cancer [7].

Romania is situated on rank 7, with an incidence of approximately 7.9 cases per 100,000 inhabitants [2] with one of the highest mortality rates in Eastern Europe [15]. The male/ female incidence has increased from 5.5/2.92 in 1955 to 8.1/4.2 in 2008 [8] and 9.3/5.1 in 2012 [16]. In the same 2012 year, PC was the third digestive cancer as incidence, and the forth digestive cancer as a cause of mortality in males, meanwhile in females, it was the second digestive cancer as incidence and the third cause of deaths from digestive cancer [17]. It has been estimated by the International Agency of Cancer that the incidence for males reached 8.9 and for females 5.3 per 100,000 inhabitants in 2018 [18]. There are few published data on risk factors in PC in Romania or the frequency on the familial history in this population [19].

The purpose of this study was to assess the risk factors in pancreatic ductal adenocarcinoma (PDAC) and familial pancreatic adenocarcinoma, to assess their presence in the adenocarcinoma patients compared to patients with neuroendocrine tumors and controls and to evaluate their predictive role on survival.

\section{METHODS}

\section{Study subjects}

For this study, we collected prospective data from patients diagnosed with PC between January 2015 and January 2017, in two Romanian tertiary medical centers. Our hospital-based study assessed the major risk factors of pancreatic cancer.

A total of 624 patients were recruited, including 312 pathologically verified cancer cases and 312 controls selected from other patients who did not have pancreatic cancer. Cases and control were 1:1 matched by gender and age. Inclusion criteria were: patients with solid pancreatic masses on ultrasonography (US) or a computed tomography (CT) scan, with or without hepatic metastases and confirmed histologically by fine needle aspiration (FNA) biopsy during endoscopic ultrasonography (EUS) or surgery. Control subjects had no cancer history and were individually matched to cases with the same gender and age (within five years). Exclusion criteria were solid pancreatic masses with no proven malignancy or cystic pancreatic masses.

All subjects gave informed consent before being included in the study. The study was approved by the Ethics Committee of both hospitals.

\section{Data collection}

We collected information regarding demographic data, data on possible risk factors, symptoms, diagnosis, staging, therapy, and survival. Demographic data included age and gender of patients. Information regarding alcohol consumption and smoking (the average number of cigarettes smoked daily; a pack-year was defined as twenty cigarettes smoked daily for one year), body mass index (BMI), history of chronic pancreatitis, diabetes mellitus, $\mathrm{B}$ or $\mathrm{C}$ viral hepatitis, abdominal surgeries, and familial PC was collected as possible risk factors. Based on BMI, the patients were classified as underweight $(<18.5 \mathrm{~kg} /$ $\left.\mathrm{m}^{2}\right)$, normal $\left(18.5-24.9 \mathrm{~kg} / \mathrm{m}^{2}\right)$, overweight $\left(25\right.$ to $\left.29.9 \mathrm{~kg} / \mathrm{m}^{2}\right)$, and obese $\left(>30 \mathrm{~kg} / \mathrm{m}^{2}\right)$. Diabetes mellitus was considered as unrelated to the occurrence of PC when it was diagnosed $\geq 3$ years before the diagnosis of PC. Fasting blood samples were collected to determine the levels of glucose, HDL-cholesterol and triglycerides. Diabetes mellitus was diagnosed when fasting glycemia was $\geq 126 \mathrm{mg} / \mathrm{dl}$. The metabolic syndrome was assessed using the IDF criteria [20]: central obesity (waist circumference $>94 \mathrm{~cm}$ in men and $>80 \mathrm{~cm}$ in women or $\mathrm{BMI}>30 \mathrm{~kg} / \mathrm{m}^{2}$ no matter the waist circumference $\left.[21,22]\right)$, fasting plasma glucose or previously diagnosed type 2 diabetes, high blood pressure or treatment of previously diagnosed hypertension, decreased HDL-cholesterol $(<40 \mathrm{mg} / \mathrm{dl}$ in males, $<50 \mathrm{mg} / \mathrm{dl}$ in females), and increased triglyceride $\geq 150$ $\mathrm{mg} / \mathrm{dl}$. Using IDF criteria, metabolic syndrome was defined as central obesity plus any two of the other four components listed above [20].

Familial PC was considered when any of the first-degree relatives had PC.

Cancer-related data included the date of diagnosis, staging, localization of the primary tumor, treatment, and the level of CA 19-9 at the time of diagnosis.

Diagnosis and staging of pancreatic cancer were based on imaging techniques CT and/or EUS, which assessed the primary resectable tumor, the locally advanced, and the metastatic disease. The final diagnosis was based on the histologic results from EUS-FNA or surgery. In neuroendocrine tumors (NET) patients, the diagnosis was made on core-histology from EUS-FNA with immunohistochemistry for chromogranin A, synaptophysin and Ki-67. The NET included were nonfunctioning tumors. The diagnosis of chronic pancreatitis was made by appearance on CT and/or EUS examination as previously described [23].

Survival was defined as the number of months between the date of diagnosis and date of death. The date of diagnosis was defined as the time from the first imaging modality (CT or EUS) giving the diagnosis of pancreatic cancer.

\section{Statistical analyses}

Categorical data were presented as count and relative frequencies. Continuous data were presented as means and standard deviations for normally distributed data and as medians with 25\% and 75\% percentiles, for skewed data.

Potential predictors for PDAC were checked with univariate logistic regression models, followed by a multivariate logistic regression model including all of them. All models were checked for goodness-of-fit with the Hosmer-Lemeshow test. For the multivariate model we checked the multicolinearity with variance inflation factor (and removing redundant variables), misspecification (Stuckel test and Osius-Rojek test). All logistic regression models were presented with odds ratios, 95\% confidence intervals and p-values.

Potential predictors for overall survival (OS) were assessed using univariate Cox proportional hazard regression. The same predictors were then analyzed in multivariate models, adjusted 
for age (years), T stage (1-2, 3, 4), adenopathy, metastasis. Proportional hazard assumptions were checked using Schoenfeld residuals and a formal test. The multicollinearity assumption was verified with the variance inflation factor for the multivariable models. For continuous variables, the linearity was checked with penalized smoothing splines. All models shown adhere to these assumptions. Hazard ratios and $95 \%$ confidence intervals are shown for the models. For all analyses, two-sided p-values were shown, and a 0.05 level of significance was used.

All analyses were performed in $\mathrm{R}$ environment for statistical computing and graphics (R Foundation for Statistical Computing, Vienna, Austria), version 3.4.3.

\section{RESULTS}

There were 624 patients included in the study, 312 with suspected PC and 312 healthy persons as controls. Mean age of the entire cohort was 63.4 years (SD 12.18, ranging from 16 to 91 years). There were more males than females ( $n=183,59 \%$ vs. $\mathrm{n}=129,41 \%)$ in patients with suspected PC and also in control group ( $n=193,62 \%$ vs $n=119,38 \%)$. Mean age of patients with PDAC was $64.88 \pm 10.74$ years old compared to $62.42 \pm 13.29$ years old ( $p>0.05)$. The most frequent symptoms in patients suspected of PC were abdominal pain and weight loss, which were present in $83 \%$ and $68 \%$ of all patients. Jaundice was found in $38 \%$. Diarrhea was recorded in $18 \%$ of the patients, $29 \%$ had constipation.

The characteristics of PDAC and NET patients are displayed in Table I. In $90 \%$ of patients we identified histologically PDAC and in $8 \%$ NET. There were 3 cases (1\%) of adenosquamous carcinoma of pancreas, 2 cases (1\%) of mucinous adenocarcinoma of the pancreas, and one case each of solid pseudopapillary neoplasm, signet ring cell carcinoma, undifferentiated carcinoma with osteoclast-like cells, and one of pancreatic metastases of squamous carcinoma. The age, gender, and size of the tumor were similar in the two categories of patients. The high level of CA 19-9 was more frequent in PDAC than in NET $(\mathrm{p}<0.001)$. The presence of metabolic syndrome was noted in $4.3 \%$ of patients with PDAC and in $16.7 \%$ of patients with NET.

Univariate analysis showed that age over 60 years (OR: 1.7, 95\%CI: 1.22-2.38), cigarette smoking (OR: 1.49, 95\%CI: 1.07-2.08), low BMI (OR: 10.67, 95\%CI: 4.74-28.61) and high BMI (OR: 2.12, 95\%CI: 1.18-3.86), diabetes (OR: 4.1, 95\%CI: 2.59-6.61), and the presence of new-onset diabetes (OR: 11.78, 95\%CI: 5.28-31.42) were associated with an increased risk of pancreatic cancer. In multivariate analyses, after adjusting for age $>60$ years, smoking, alcohol and coffee consumption, weight status, diabetes and new-onset diabetes, hepatitis B virus (HBV), hepatitis $\mathrm{C}$ virus (HCV), cholecystectomy and biliary lithiasis, we found that advanced age (OR: 1.67), smoking (OR: 1.67), low body mass index (OR: 12.07), and diabetes (OR: 3.91) with the presence of new-onset diabetes (OR: 12.97) were associated with elevated risk (Table II).

No differences for the frequency of risk factors (smoking, alcohol consumption, diabetes and familial history of pancreatic cancer) was found between PDAC and NET, except for the median BMI $\left(24.24 \mathrm{~kg} / \mathrm{m}^{2}\right.$ in PDAC vs $27.55 \mathrm{~kg} / \mathrm{m}^{2}$ in
NET, $\mathrm{p}=0.013)$. Also, the association with the presence of $\mathrm{HCV}$ was significantly higher in patients with NET (12.5\% in NET vs $7.53 \%$ in PDAC, $\mathrm{p}=0.027)$. The rate of diabetes $(41.2 \%$ in PDAC and $37.5 \%$ in NET, $\mathrm{p}=0.72$ ) was similar. There was no difference regarding smoking in the 2 groups ( $43.37 \%$ in PDAC and $29.17 \%$ in NET) $(\mathrm{p}=0.176)$.

More than $40 \%$ of patients with PDAC had metastases, compared to $20 \%$ of patients with NET ( $\mathrm{p}=0.037$ ).

Positive family history for pancreatic adenocarcinoma was found in 13 patients (4\%) with PC (12 patients with PDAC and one patient with NET). For the analysis of the influence of familial history, the NET patient was excluded (Table III). The presence of new-onset diabetes was associated with an elevated risk of familial PC (OR: 4.64, $\mathrm{p}=0.018$ ).

At 38 months of follow up, almost $73 \%$ of patients with PDAC had died. The median overall OS was 9 months for the 279 patients with PDAC. This was significantly different in relation to the advanced tumor stage $(p=0.001)$ and the presence of metastases $(\mathrm{p}<0.001)$ in a Kaplan-Meier analysis.

There was no association between risk factors (obesity, history of chronic pancreatitis, diabetes, smoking, familial pancreatic cancer, etc.) and OS.

In a multivariate Cox- proportional survival analysis, we assessed several variables after adjustment for T stage (1-2, $3,4)$, malignant lymph nodes, and metastasis. Still, only advanced tumoral stage $(\mathrm{HR}=1.6, \mathrm{p}=0.003)$ was identified as an independent predictor for OS (Table IV).

\section{DISCUSSION}

The mortality rate of PC in Central Europe is one of the highest in the world [15] and decreases in the immediate vicinity in Eastern Europe countries, such as Romania [2]. There is no explanation for this difference, and it is very important to know which are the factors involved in the development of the disease. This work brings together and assesses two groups of the PC population from the northwestern part and the eastern part of Romania. Less than $10 \%$ were NET and from all the population included, only $4 \%$ recognized history of pancreatic cancer in this bi-centric study, which is consistent with the literature data showing that the familial history of PC increases risk and accounts for $4-16 \%$ of cases [24]. A previous retrospective study made on a Romanian population in one tertiary medical center of 148 patients found $1 \%$ history of PC in the population over 45 years old [19], which is consistent with $4 \%$ in our group with a median age of 61 years old.

Several studies revealed that smoking [9] and the recent onset of diabetes [10] are supplementary risk factors for familial PC. Consistent with these results, we found that there was a significantly elevated risk of familial PC for patients with new-onset diabetes (OR: 4.64). Moreover, in patients with familial PC 50\% of patients were smokers, and 33\% of them drank alcohol, but the difference was not significant compared to non-familial PC. The age of these patients was similar compared to patients with no family history of PC (61.08 vs. 64.61).

Pancreatic cancer is predominantly a disease of older individuals and almost $90 \%$ of patients with PC are diagnosed 
Table I. Demographic characteristic of patients with pancreatic adenocarcinoma and pancreatic neuroendocrine tumors

\begin{tabular}{|c|c|c|c|}
\hline Characteristic & $\begin{array}{l}\text { PDAC patients } \\
\quad(\mathrm{n}=279)\end{array}$ & $\begin{array}{c}\text { NET patients } \\
(\mathrm{n}=24)\end{array}$ & $\mathrm{p}$ \\
\hline Age (years), mean (SD) [range] & $64.88(10.74)[35-89]$ & $62.04(10.51)[27-82]$ & 0.21 \\
\hline Age $>60$ years, $n(\%)$ & $187(67.03)$ & $15(62.5)$ & 0.65 \\
\hline Gender (female), $\mathrm{n}(\%)$ & $114(40.86)$ & $12(50)$ & 0.383 \\
\hline Triglycerides (mg/dL), median (IQR) [range] & $127(93-191)[42-535]$ & $117.5(74-153)[52-245]$ & 0.22 \\
\hline HDL-cholesterol (mg/dL), median (IQR) [range] & $29(20-44)[5-81]$ & $17.5[15-20]$ & 0.28 \\
\hline BMI, median (IQR) & $24.24(21.66-26.72)$ & $27.55(23.43-30.62)$ & 0.014 \\
\hline Normal weight, $\mathrm{n}(\%)$ & $121(43)$ & $8(33)$ & 0.4 \\
\hline Underweight, n (\%) & $44(15.3)$ & $1(4.2)$ & 0.22 \\
\hline Overweight, n (\%) & $116(40.3)$ & $16(66.7)$ & 0.06 \\
\hline Obese, $\mathrm{n}(\%)$ & $32(11.5)$ & $7(29.2)$ & 0.043 \\
\hline Fasting blood glucose (mg/dL), mean (SD) [range] & $149.18(60.1)[58-473]$ & $130.3(53.5)[80-292]$ & 0.08 \\
\hline Arterial hypertension, $\mathrm{n}(\%)$ & $124(44.4)$ & $24(58.3)$ & 0.2 \\
\hline Metabolic syndrome, n (\%) & $12(4.3)$ & $4(16.7)$ & 0.029 \\
\hline CA 19-9 (U/ml) $>37$ UI/l, median (IQR) [range] & $191(45-400)[1-400]$ & $16(8.21-72.95)[1-400]$ & $<0.001$ \\
\hline Tumor size $>=3 \mathrm{~cm}, \mathrm{n}(\%)$ & $231(82.8)$ & $18(75)$ & 0.401 \\
\hline \multicolumn{4}{|l|}{ T stage, $\mathrm{n}(\%)$} \\
\hline $\mathrm{T} 1-2$ & $26(9.3)$ & $4(16.7)$ & 0.08 \\
\hline $\mathrm{T} 3$ & $100(35.8)$ & $12(50)$ & 0.2 \\
\hline $\mathrm{T} 4$ & $153(54.8)$ & $8(33.33)$ & 0.043 \\
\hline Stage III-IV, n (\%) & $168(60.2)$ & $9(37.5)$ & 0.04 \\
\hline \multicolumn{4}{|l|}{ Pancreatic cancer location } \\
\hline Head + uncinated process + isthmus, $n(\%)$ & $183(65.6)$ & $13(54.2)$ & 0.367 \\
\hline Body + tail, n (\%) & $96(34.4)$ & $11(45.8)$ & \\
\hline \multicolumn{4}{|l|}{ Histological grade, $\mathrm{n}(\%)$} \\
\hline G1 & 9/77 (11.84) & $2 / 4(50)$ & \\
\hline $\mathrm{G} 2$ & $39 / 77(51.32)$ & $2 / 4(50)$ & 0.085 \\
\hline G3 & 28/77 (36.84) & $0 / 4(0)$ & \\
\hline $\mathrm{N}$ stage $\mathrm{n}(\%)$ & $230(82.44)$ & $16(66.67)$ & 0.097 \\
\hline Metastasis, n (\%) & $119(42.65)$ & $5(20.83)$ & 0.037 \\
\hline Chemotherapy, n (\%) & $163(77.25)$ & $17(89.47)$ & 0.381 \\
\hline \multicolumn{4}{|l|}{ Endoscopic palliative biliary drainage: } \\
\hline biliary plastic stents, $\mathrm{n}(\%)$ & $56(20)$ & $4(17)$ & 0.336 \\
\hline metal stents, n (\%) & $37(13)$ & $2(8)$ & \\
\hline External biliary drainage & $4(1)$ & & \\
\hline Palliative surgical drainage (enteral and biliary bypass) & $43(15)$ & $3(12.5)$ & \\
\hline
\end{tabular}

PDAC: pancreatic adenocarcinoma; NET: neuroendocrine tumors; CA 19-9: Carbohydrate antigen 19-9; SD: standard deviation; IQR: interquartile range; BMI: body mass index; HDL: high density lipids

after the age of 55 years $[1,25]$, as in our study, although $33 \%$ of patients were younger than this cut-off age. Also, the mortality in both genders increases with age, especially after the age of 55 years $[2,26]$. In our study, mortality was higher in patients over 60 years, although its independent role in predicting survival was not proved, results similar to those in the literature [27] (Table IV).

Many studies have confirmed that smoking increases the risk of PC up to 6 times [28]. A meta-analysis reported that smokers were at twice the risk of PC compared to non-smokers, and the number of cigarettes smoked and the duration of smoking were associated with an increasing trend of elevated risk $[29,30]$. The cessation of cigarette smoking for less than five years and the exposure to tobacco smoke during childhood or at home or work are associated with PC. Still, it was reduced in non-smokers within five years of quitting [30]. The association of coffee consumption found no additional risk [31]. According to the latest Eurobarometer survey, 31\% of the Romanian population regularly smokes (33\% of men and $22 \%$ women) $[32,33]$. In our study, we found a higher percentage of smokers (43\% of patients with PDAC, $29 \%$ of patients with NET and 34\% in controls) significantly associated with PC risk (OR: 1.67) (Table III). Smoking did not influence the survival in pancreatic cancer, as in the literature [34]. 
Table II. Frequency of possible risk factors for patients with pancreatic ductal adenocarcinoma

\begin{tabular}{|c|c|c|c|c|}
\hline Risk factors & PDAC $(\mathrm{n}=279)$ & Controls $(n=312)$ & $\mathrm{p}$ & OR adjusted $(95 \% \mathrm{CI})$ \\
\hline Age $>60$ years & $187(67)$ & $170(54.2)$ & 0.002 & $1.67(1.13-2.48)$ \\
\hline Smoking, n (\%) & $121(43.37)$ & $106(34)$ & 0.02 & \\
\hline$>20$ pack-year & $74(27)$ & $53(17)$ & 0.005 & $1.67(1.09-2.59)$ \\
\hline Alcohol consumption, n (\%) & $128(45.88)$ & $138(44.2)$ & 0.688 & $0.92(0.62-1.38)$ \\
\hline \multicolumn{5}{|l|}{ Coffee consumption, n (\%) } \\
\hline Moderate & $141(50.57)$ & $179(57)$ & 0.09 & $0.65(0.44-0.97)$ \\
\hline Excessive & $7(2.51)$ & $5(1.6)$ & & \\
\hline None & $131(46.95)$ & $128(41)$ & & \\
\hline \multicolumn{5}{|l|}{ Weight status, n (\%) } \\
\hline Normal weight & $121(43)$ & $173(56)$ & & \\
\hline Underweight & $44(15.3)$ & $6(1.9)$ & & \\
\hline Overweight & $116(40.3)$ & $130(41.7)$ & $<0.001^{\circ}$ & $12.07(5.03-34.32)$ \\
\hline Obese & $32(11.5)$ & $22(7.1)$ & $0.253^{*}$ & $1.49(0.75-2.95)$ \\
\hline Metabolic syndrome, n (\%) & $12(4.3)$ & $12(3.8)$ & 0.8 & $1.02(0.43-2.38)$ \\
\hline Chronic pancreatitis, n (\%) & $37(13.26)$ & $35(1.2)$ & 0.7 & \\
\hline Alcoholic etiology, n (\%) & $22(7.97)$ & $22(7.1)$ & 0.13 & $0.77(0.42-1.41)$ \\
\hline Diabetes, n (\%) & $115(41.22)$ & $36(11.5)$ & 0.001 & $3.91(2.38-6.54)$ \\
\hline Insulin treatment & $44(16)$ & $11(4)$ & & \\
\hline Oral antidiabetics & $62(22)$ & $22(7)$ & & \\
\hline New-onset diabetes, n (\%) & $42(15)$ & $6(1.9)$ & $<0.001$ & $12.97(5.54-35.92)$ \\
\hline Familial PDAC history, n (\%) & $12(4.3)$ & $0(0)$ & $\leq 0.001$ & NA \\
\hline HCV, n (\%) & $6(2.15)$ & $13(4.2)$ & 0.17 & $0.31(0.09-0.93)$ \\
\hline $\mathrm{HBV}, \mathrm{n}(\%)$ & $2(0.72)$ & $9(2.9)$ & 0.06 & $0.24(0.03-1.16)$ \\
\hline Cholecystectomy, n (\%) & $48(17.2)$ & $40(12.8)$ & 0.214 & $1.15(0.68-1.96)$ \\
\hline Biliary lithiasis, n (\%) & $21(7.53)$ & $31(9.9)$ & 0.39 & $0.62(0.32-1.19)$ \\
\hline
\end{tabular}

Epidemiological studies showed that the alcohol-abusing group has a higher PC incidence and mortality than nondrinkers and heavy alcohol drinkers had a relative risk of 1.36 compared to light drinkers and 1.29 compared to non-drinkers [35], with chronic pancreatitis being one carcinogenic pathway. In our studied population, regular consumption of alcohol was reported in almost $46 \%$ of the PDAC patients, among which $8 \%(n=22)$ had chronic alcoholic pancreatitis, and this is higher than in the published literature where it was stated that $5 \%$ of patients with chronic pancreatitis developed PC [36]. Statistical analysis proved that alcohol consumption represented no risk factor for PDAC or NET.

The association between diabetes and PDAC is well-known [37] and new-onset diabetes proved the strongest association with this disease [38]; this was confirmed both in patients with a familial history of PC as well in sporadic PDAC. Overall, $41 \%$ of our patients with PDAC had diabetes, compared to $50 \%$ in other published data [39]. Almost 15\% of patients had newonset diabetes, which was an important risk factor for PDAC (OR: 12.97). However, long-standing diabetes, accepted as a risk factor in other reports [40], was not confirmed in our group.

In addition to diabetes, obesity, and overweight patients were considered at risk for PC [41-44]. Overweight and obese people had a $10 \%$, respectively $20 \%$ increased risk of PC compared with people of normal weight [45]. There are many possible mechanisms by which obesity can lead to PC, including insulin resistance with resulting hyperinsulinemia and inflammation [41]. In our study, BMI $<18.5 \mathrm{~kg} / \mathrm{m} 2$, but not obesity, was a risk factor for PDAC in the multivariate analysis (OR: 12.07), a fact reported also by another study [42]. This may be explained by the advanced tumor stages of patients included (60\% stage III and IV tumors), associated with underweight and cachexia. Furthermore, the BMI was significantly higher in patients with NET vs. PDAC (29\% vs. $11 \%, \mathrm{p}=0.043)$. This is similar to the results of a meta-analysis [46], although contradictory findings exist [47]. However, we found no association of obesity with survival in PC, contrary to other studies that showed that obesity is associated with poorer survival $[43,44,48]$. Previous reports proved a $31-47 \%$ increased risk of PC patients with metabolic syndrome [21, 49, 50], but this was not confirmed in our study. The prevalence of the metabolic syndrome in population with cardiovascular diseases in Romania is up to $40 \%$ [51], but recent data in general population are lacking. In our patients with pancreatic adenocarcinoma we found the association with metabolic syndrome in $4.3 \%$, which is lower than in other studies (8.46\%) with the same criteria for defining the metabolic syndrome 
Table III. Characteristics of patients with familial pancreatic cancer

\begin{tabular}{|c|c|c|c|c|}
\hline Familial pancreatic cancer & Yes $(n=12)$ & No $(n=300)$ & $\mathrm{p}$ & OR (95\%CI) \\
\hline Age (years), mean $(\mathrm{SD})^{*}$ & $61.08(11.59)$ & $64.61(10.80)$ & 0.3 & \\
\hline Age $\leq 60$ years $($ yes $), \mathrm{n}(\%)$ & $6(50)$ & $98(32.78)$ & 0.224 & $2.06(0.64-6.55)$ \\
\hline Gender (female), n (\%) & $8(66.7)$ & $121(40.3)$ & 0.08 & $2.35(0.75-7.36)$ \\
\hline BMI $(\mathrm{kg} / \mathrm{cm} 2)$, median (IQR) & $23.8(21.67-25.39)$ & $24.4(21.77-27.15)$ & 0.824 & \\
\hline \multicolumn{5}{|l|}{ Localization } \\
\hline Head + isthmus + uncinate process, $\mathrm{n}(\%)$ & $7(58.3)$ & $189(64.9)$ & 0.759 & $1.14(0.35-3.69)$ \\
\hline Body + tail, n (\%) & $5(41.7)$ & $102(35.1)$ & & \\
\hline Smoking, n (\%) & $6(50)$ & $129(43)$ & 0.63 & $1.32(0.41-4.2)$ \\
\hline Alcohol, n (\%) & $4(33.3)$ & $141(47)$ & 0.35 & $0.56(0.16-1.91)$ \\
\hline New-onset diabetes, n (\%) & $5(41.7)$ & $40(13.3)$ & 0.018 & $4.64(1.4-15.33)$ \\
\hline Long-standing diabetes, n (\%) & $1(8.3)$ & $80(26.7)$ & 0.19 & $0.25(0.03-1.96)$ \\
\hline Metabolic syndrome, n (\%) & $1(8.3)$ & $11(4.1)$ & 0.41 & $1.35(0.15-11.9)$ \\
\hline
\end{tabular}

SD: standard deviation; IQR: interquartile range; BMI: body mass index; OR: odds ratio.

[52], but the difference compared to the control group was not significant.

The presence of metabolic syndrome in patients with NET was significantly higher than in PDAC $(16.7 \%$ vs $4.3 \%$, $\mathrm{p}=0.029$ ) explained by the fact that BMI was significantly higher in patients with NET, as previously described [53].
Surprisingly, we found the frequency of HCV infection higher in NET cases compared to PDAC, but this is most likely to be an incidentaloma rather than the pancreatic disease itself.

The assessment of OS revealed the median OS for patients with PDAC was nine months and the advanced tumor stage was correlated with poorer survival. In the literature, at the

Table IV. Univariate and multivariate analysis to predict overall survival for patients with pancreatic ductal adenocarcinoma

\begin{tabular}{|c|c|c|c|c|}
\hline & Univariate analyses & & Multivariate analyses & \\
\hline & HR unadjusted (95\% CI) & $\mathrm{p}$ & HR adjusted $(95 \% \mathrm{CI})$ & $\mathrm{p}$ \\
\hline Age (years) & $1.02(0.9-1.04)$ & 0.2 & $1.01(0.99-1.02)$ & 0.06 \\
\hline Age $>60$ years & $1.3(0.96-1.75)$ & 0.089 & $1.28(0.95-1.73)$ & 0.09 \\
\hline Gender & $1(0.76-1.33)$ & 0.979 & $1.01(0.76-1.34)$ & 0.938 \\
\hline Tumor stage T3 vs. T1-2 & $1.06(0.71-1.58)$ & 0.775 & $1.04(0.7-1.55)$ & 0.836 \\
\hline Tumor stage T4 vs. T1-2 & $1.19(0.9-1.57)$ & 0.211 & $0.64(0.39-1.05)$ & 0.078 \\
\hline Stage IV & $1.66(1.22-2.25)$ & 0.001 & $1.6(1.17-2.18)$ & 0.003 \\
\hline Lymph nodes N1 & $1.14(0.78-1.65)$ & 0.494 & $0.87(0.58-1.31)$ & 0.506 \\
\hline Tumor size $>=3 \mathrm{~cm}$ & $1.32(0.9-1.93)$ & 0.157 & $1.21(0.82-1.78)$ & 0.336 \\
\hline Metastases & $1.67(1.27-2.2)$ & $<0.001$ & $1.79(0.64-5.03)$ & 0.269 \\
\hline Obesity & $0.81(0.52-1.28)$ & 0.374 & $0.89(0.56-1.4)$ & 0.605 \\
\hline Smoking & $0.83(0.62-1.09)$ & 0.18 & $0.87(0.65-1.15)$ & 0.328 \\
\hline Alcohol & $1.16(0.88-1.52)$ & 0.299 & $1.11(0.84-1.46)$ & 0.46 \\
\hline Coffee consumption & $1.29(0.57-2.96)$ & 0.54 & $1.13(0.49-2.6)$ & 0.767 \\
\hline Diabetes & $0.89(0.67-1.17)$ & 0.395 & $0.87(0.66-1.16)$ & 0.345 \\
\hline Metabolic syndrome & $0.72(0.45-1.6)$ & 0.39 & $0.83(0.54-1.28)$ & 0.41 \\
\hline $\mathrm{HCV}$ & $0.69(0.26-1.87)$ & 0.471 & $0.75(0.27-2.03)$ & 0.567 \\
\hline $\mathrm{HBV}$ & $2.06(0.51-8.34)$ & 0.311 & $1.84(0.45-7.49)$ & 0.392 \\
\hline Genetic factors & $1.03(0.54-1.94)$ & 0.939 & $1.03(0.54-1.96)$ & 0.926 \\
\hline Blood group A2 & $1.62(0.88-3.00)$ & 0.11 & $1.58(0.87-2.86)$ & 0.13 \\
\hline Cholecystectomy & $0.89(0.61-1.28)$ & 0.522 & $0.9(0.62-1.31)$ & 0.588 \\
\hline $\begin{array}{l}\text { History of chronic } \\
\text { pancreatitis }\end{array}$ & $1.03(0.69-1.53)$ & 0.891 & $1.12(0.74-1.67)$ & 0.597 \\
\hline Chemotherapy & $0.9(0.62-1.3)$ & 0.577 & $0.75(0.5-1.12)$ & 0.162 \\
\hline
\end{tabular}


time of diagnosis, only approximately $20 \%$ of patients with PC have a resectable disease $[54,55]$. Still, in our group, only $9 \%$ were resectable, and this may explain the low survival duration. More than $40 \%$ of PDAC patients had metastasis compared to only $20 \%$ in the NET patients. However, because the number of patients with NET was low, we refrained from evaluating the predictive factors for survival in these patients.

Although the study was prospective, there are several limitations to our results. First of all, the group included was a hospital population where the patients addressed obtained a pathological diagnosis, and this could explain the low rate of resectability. Secondly, the patients were included from only two regions of the country and may not be representative for the entire population of Romania. Thirdly, the number of patients included was small $(n=312)$, and a larger cohort would have been helpful to obtain good epidemiological data in Romania. Moreover, the number of patients with NET was relatively small, so we had insufficient data for survival analysis in this subgroup.

Although in our study we did not find any correlation between risk factors and survival in PC, the recognition and control of risk factors can provide opportunities to improve prognosis.

\section{CONCLUSIONS}

Our data suggest that diabetes, smoking, underweight, and age over 60 years are risk factors for PDAC. Besides the known risk factors for PC, a family history of PC is an important risk factor to consider for screening. Patients with a family history of PC, especially those with new-onset diabetes, should be followed carefully and considered for screening studies in order to detect early PC. There was no association between gender, smoking, alcohol consumption, diabetes, presence of overweight or obesity, chronic pancreatitis and OS. Advanced tumor stage was identified as an independent predictor for OS.

Conflicts of interests: None to declare.

Authors' contribution: L.P., A.S. designed the study and drafted the manuscript. L.P., M.B., V.D., A.S. collected the data. D.C.L performed data analyses. A.S. performed the endoscopic procedures. V.D., D.C.L, C.C, R.S, A.S. critically revised the manuscript. All authors approved the final version to be published, and agree to be accountable for all aspects of the work.

\section{REFERENCES}

1. Ilic M, Ilic I. Epidemiology of pancreatic cancer. World J Gastroenterol 2016;22:9694-9705. doi:10.3748/wjg.v22.i44.9694

2. Bray F, Ferlay J, Soerjomataram I, Siegel RL, Torre LA, Jemal A. Global cancer statistics 2018: GLOBOCAN estimates of incidence and mortality worldwide for 36 cancers in 185 countries. CA Cancer J Clin 2018;68:394-424. doi:10.3322/caac.21492

3. Malvezzi M, Bertuccio P, Levi F, La Vecchia C, Negri E. European cancer mortality predictions for the year 2014. Ann Oncol 2014;25:1650-1656. doi:10.1093/annonc/mdu138
4. American Cancer Society. Cancer facts \& figures 2008. Available at:https://www.cancer.org/research/cancer-facts-statistics/all-cancerfacts-figures/cancer-facts-figures-2008.html

5. Bray F, Sankila R, Ferlay J, Parkin DM. Estimates of cancer incidence and mortality in Europe in 1995. Eur J Cancer 2002;38:99-166. doi:10.1016/ S0959-8049(01)00350-1

6. Ryan DP, Hong TS, Bardeesy N. Pancreatic Adenocarcinoma. N Engl J Med 2014;371:1039-1049. doi:10.1056/NEJMra1404198

7. Biadgo B, Abebe M. Type 2 diabetes mellitus and its association with the risk of pancreatic carcinogenesis: a review. Korean J Gastroenterol 2016;67:168-177. doi:10.4166/kjg.2016.67.4.168

8. Valean S, Armean P, Resteman S, Nagy G, Muresan A, Mircea PA. Cancer mortality in Romania, 1955-2004. Digestive sites: esophagus, stomach, colon and rectum, pancreas, liver, gallbladder and biliary tree. J Gastrointestin Liver Dis 2008;17:9-14.

9. Yeo TP, Hruban RH, Brody J, Brune K, Fitzgerald S, Yeo CJ. Assessment of "gene-environment" interaction in cases of familial and sporadic pancreatic cancer. J Gastrointest Surg 2009;13:1487-1494. doi:10.1007/ s11605-009-0923-6

10. Matsubayashi H, Maeda A, Kanemoto H, et al. Risk factors of familial pancreatic cancer in Japan: current smoking and recent onset of diabetes. Pancreas 2011;40:974-978. doi:10.1097/MPA.0b013e3182156e1b

11. McGuigan A, Kelly P, Turkington RC, Jones C, Coleman HG, McCain RS. Pancreatic cancer: A review of clinical diagnosis, epidemiology, treatment and outcomes. World J Gastroenterol 2018;24:4846-4861. doi:10.3748/wjg.v24.i43.4846

12. Luo G, Zhang Y, Guo P, Ji H, Xiao Y, Li K. Global Patterns and Trends in Pancreatic Cancer Incidence: Age, Period, and Birth Cohort Analysis. Pancreas 2019;48:199-208. doi:10.1097/MPA.0000000000001230

13. Ding Y, Yu C, Han Z, et al. Environmental tobacco smoke and pancreatic cancer: a case-control study. Int J Clin Exp Med 2015;8:16729-16732.

14. Rebours V, Boutron-Ruault MC, Schnee M, et al. Risk of pancreatic adenocarcinoma in patients with hereditary pancreatitis: a national exhaustive series. Am J Gastroenterol 2008;103:111-119.

15. Hariharan D, Saied A, Kocher HM. Analysis of mortality rates for pancreatic cancer across the world. HPB (Oxford) 2008;10:58-62. doi:10.1080/13651820701883148

16. Valean S, Acalovschi M, Diculescu M, et al. Mortality in Digestive Cancers, 2012: International Data and Data from Romania. J Gastrointestin Liver Dis 2015;24:507-514. doi:10.15403/jgld.2014.1121.244.rom

17. Valean S, Chira R, Dumitrascu D. Epidemiological trends in digestive cancers in Romania, 1955-2012, compared to alcohol consumption. Correlation or coincidence? Clujul Med 2018;91:376-386. doi:10.15386/ cjmed-1067

18. Ferlay J, Ervik M, Lam F, et al. (Eds.). Global Cancer Observatory: Cancer Today Data visualization tools for exploring the global cancer burden in 2018. Available at:https://gco.iarc.fr/today/home

19. Bunduc S, Iacob R, Costache R, Stoica B, Radu C, Gheorghe C. Very Early Onset Pancreatic Adenocarcinoma-Clinical Presentation, Risk Factors and Therapeutic Options. Chirurgia (Bucur) 2018;113:405-411. doi:10.21614/chirurgia.113.3.405

20. Saely CH, Koch L, Schmid F, et al. Adult Treatment Panel III 2001 but not International Diabetes Federation 2005 criteria of the metabolic syndrome predict clinical cardiovascular events in subjects who underwent coronary angiography. Diabetes Care 2006;29:901-907. doi:10.2337/diacare.29.04.06.dc05-2011

21. Xia B, He Q, Pan Y, et al. Metabolic syndrome and risk of pancreatic cancer: Apopulation-based prospective cohort study. Int J Cancer 2020 Jun 24. doi:10.1002/ijc.33172 
22. Alberti KGMM, Zimmet P, Shaw J. Metabolic syndrome - a new world-wide definition. A consensus statement from the international diabetes federation. Diabet Med 2006;23:469-480. doi:10.1111/j.14645491.2006.01858.x

23. Conwell DL, Lee LS, Yadav D, et al. American Pancreatic Association Practice Guidelines in Chronic Pancreatitis: evidence-based report on diagnostic guidelines. Pancreas 2014;43:1143-1162. doi:10.1097/ MPA.0000000000000237

24. Klein AP, Brune KA, Petersen GM, et al. Prospective risk of pancreatic cancer in familial pancreatic cancer kindreds. Cancer Res 2004;64:26342638. doi:10.1158/0008-5472.can-03-3823

25. Bosetti C, Bertuccio P, Negri E, La Vecchia C, Zeegers MP, Boffetta P. Pancreatic cancer: overview of descriptive epidemiology. Mol Carcinog 2012;51:3-13. doi:10.1002/mc.20785

26. Howlader N, Noone AM, Krapcho M, et al. SEER Cancer Statistics Review, 1975-2013. Bethesda, MD:National Cancer Institute, 2016.

27. Kaissis AG, Jungmann F, Ziegelmayer S, et al. Multiparametric Modelling of Survival in Pancreatic Ductal Adenocarcinoma Using Clinical, Histomorphological, Genetic and Image-Derived Parameters. J Clin Med 2020;9:1250. doi:10.3390/jcm9051250

28. Zhang Q, Zeng L, Chen Y, et al. Pancreatic Cancer Epidemiology, Detection, and Management. Gastroenterol Res Pract 2016;2016:8962321.

29. Iodice S, Gandini S, Maisonneuve P, Lowenfels AB. Tobacco and the risk of pancreatic cancer: a review and meta-analysis. Langenbecks Arch Surg 2008;393:535-545. doi:10.1007/s00423-007-0266-2

30. Vrieling A, Bueno-de-Mesquita HB, Boshuizen HC, et al. Cigarette smoking, environmental tobacco smoke exposure and pancreatic cancer risk in the European Prospective Investigation into Cancer and Nutrition. Int J Cancer 2010;126:2394-2403. doi:10.1002/ijc.24907

31. Zhou CD, Kuan AS, Reeves GK, et al. Coffee and pancreatic cancer risk among never-smokers in the UK prospective Million Women Study. Int J Cancer 2019;145:1484-1492. doi:10.1002/ijc.31994

32. SpecialEurobarometer429. Attitudes of Europeans towards tobacco and electronic cigarettes. TNS Opin Soc 2015. doi:10.2875/728026

33. Bogdanovica I, Godfrey F, McNeill A, Britton J. Smoking prevalence in the European Union: a comparison of national and transnational prevalence survey methods and results. Tob Control 2011;20:e4. doi:10.1136/tc.2010.036103

34. Yuan C, Morales-Oyarvide V, Babic A, et al. Cigarette smoking and pancreatic cancer survival. J Clin Oncol 2017;35:1822-1828. doi:10.1200/JCO.2016.71.2026

35. Korc M, Jeon CY, Edderkaoui M, Pandol SJ, Petrov MS; Consortium for the Study of Chronic Pancreatitis, Diabetes, and Pancreatic Cancer (CPDPC). Tobacco and alcohol as risk factors for pancreatic cancer. Best Pract Res Clin Gastroenterol 2017;31:529-536. doi:10.1016/j.bpg.2017.09.001

36. Raimondi S, Lowenfels AB, Morselli-Labate AM, Maisonneuve P, Pezzill R. Pancreatic cancer in chronic pancreatitis; aetiology, incidence, and early detection. Best Pract Res Clin Gastroenterol 2010;24:349-358. doi:10.1016/j.bpg.2010.02.007

37. Ben $Q, X u M$, Ning $X$, et al. Diabetes mellitus and risk of pancreatic cancer: a meta-analysis of cohort studies. Eur J Cancer 2011;47:19281937. doi:10.1016/j.ejca.2011.03.003

38. Wang F, Herrington M, Larsson J, Permert J. The relationship between diabetes and pancreatic cancer. Mol Cancer 2003;2:4. doi:10.1186/14764598-2-4
39. Arthur R, Kabat GC, Kim MY, et al. Adiposity, history of diabetes, and risk of pancreatic cancer in postmenopausal women. Ann Epidemiol 2019;29:23-29.e1. doi:10.1016/j.annepidem.2018.09.005

40. Wolpin BM, Bao Y, Qian ZR, et al. Hyperglycemia, Insulin Resistance, Impaired Pancreatic $\beta$-Cell Function, and Risk of Pancreatic Cancer. J Natl Cancer Inst 2013;105:1027-1035. doi:10.1093/jnci/djt123

41. Park J, Morley TS, Kim M, Clegg DJ, Scherer PE. Obesity and cancermechanisms underlying tumour progression and recurrence. Nat Rev Endocrinol 2014;10:455-465. doi:10.1038/nrendo.2014.94

42. Untawale S, Odegaard AO, Koh WP, Jin AZ, Yuan JM, Anderson KE. Body mass index and risk of pancreatic cancer in a Chinese population. PLoS One 2014;9:e85149. doi:10.1371/journal.pone.0085149

43. Li D, Morris JS, Liu J, et al. Body mass index and risk, age of onset, and survival in patients with pancreatic cancer. JAMA 2009;301:2553-2562. doi:10.1001/jama.2009.886

44. McWilliams RR, Matsumoto ME, Burch PA, et al. Obesity adversely affects survival in pancreatic cancer patients. Cancer 2010;116:50545062. doi: 10.1002/cncr.25465

45. Maisonneuve P, Lowenfels AB. Risk factors for pancreatic cancer: a summary review of meta-analytical studies. Int J Epidemiol 2014;44:186-198. doi:10.1093/ije/dyu240

46. Leoncini E, Carioli G, La Vecchia C, Boccia S, Rindi G. Risk factors for neuroendocrine neoplasms: a systematic review and meta-analysis. Ann Oncol 2015;27:68-81. doi:10.1093/annonc/mdv505

47. Valente R, Hayes AJ, Haugvik SP, et al. Risk and protective factors for the occurrence of sporadic pancreatic endocrine neoplasms. Endocr Relat Cancer 2017;24:405-414. doi:10.1530/ERC-17-0040

48. Fleming JB, Gonzalez RJ, Petzel MQB, et al. Influence of obesity on cancer-related outcomes after pancreatectomy to treat pancreatic adenocarcinoma. Arch Surg 2009;144:216-221. doi:10.1001/ archsurg.2008.580

49. Park SK, Oh CM, Kim MH, Ha E, Choi YS, Ryoo JH. Metabolic syndrome, metabolic components, and their relation to the risk of pancreatic cancer. Cancer 2020;126:1979-1986. doi:10.1002/ cncr.32737

50. Esposito K, Chiodini P, Colao A, Lenzi A, Giugliano D. Metabolic syndrome and risk of cancer: a systematic review and meta-analysis. Diabetes Care 2012;35:2402-2411. doi:10.2337/dc12-0336

51. Matei C, Pop I, Jurcut R, et al. Romanian multicentric study of the prevalence of metabolic syndrome-ROMES. Hellenic J Cardiol 2008;49:303-309.

52. Raviv NV, Sakhuja S, Schlachter M, Akinyemiju T. Metabolic syndrome and in-hospital outcomes among pancreatic cancer patients. Diabetes Metab Syndr 2017;11 Suppl 2:S643-S650. doi:10.1016/j. dsx.2017.04.019

53. Santos AP, Santos AC, Castro C, et al. Visceral obesity and metabolic syndrome are associated with well-differentiated gastroenteropancreatic neuroendocrine tumors. Cancers (Basel) 2018;10:293. doi:10.3390/ cancers 10090293

54. Li D, Xie K, Wolff R, Abbruzzese JL. Pancreatic cancer. Lancet 2004;363:1049-1057. doi:10.1016/S0140-6736(04)15841-8

55. Lakatos G, Balázs A, Kui B, et al. Pancreatic Cancer: Multicenter Prospective Data Collection and Analysis by the Hungarian Pancreatic Study Group. J Gastrointestin Liver Dis 2016;25:219-225. doi:10.15403/ jgld.2014.1121.252.pcr 